\title{
An Experimental Phonetic Study of Dialectal Impact on English Learners' Prosody_A Case Study of Shandong Dialect ${ }^{*}$
}

\author{
WANG Pei-juan, ZHAI Hong-hua \\ Shandong Agricultural University, Tai’an, China
}

\begin{abstract}
It has been commonly recognized by the academic community that Chinese English learners can be regarded as the trilingual learners in dialects, Mandarin, and then English. Thus the first two acquired languages seem to be unavoidable to result in some effects on the study of English, especially the prosody of English. At the same time, the fact that the English prosodic research has been a significant project in the linguistic study with the globalization and localization of English, draws the public's attention to the further study of the prosody of English for which is of vital importance in English learning. Focusing on the intonation, stress, tone, pause, and so on, prosody is the fundamental element of speech and the core of English phonetics. Taking Shandong dialect as an example, the study investigates the influence of the dialects on the learning of English prosody from two aspects-intonation and stress, by the acoustic analysis and comparison of the English prosody of linguistic data from Shandong EFL learners and English native speakers based on IViE (Intonational Variation in English) and ToBI (Tone and Breaks Indices) systems using Praat software. In addition, the reasons why these effects and problems take place are discussed profoundly. Therefore the corresponding measures should be taken in order to help students eliminate the negative impacts of their dialects and deliver standard English. The study may have great references on the improvement and elevation of teaching methods on the dialectal regions and some implications on second language acquisition.
\end{abstract}

Keywords: Shandong dialects, prosody, intonation, stress, effects

\section{Introduction}

In our daily life, the mistakes made by the EFL learners on their oral English in the dialectal regions can be found all the time. English native speakers could tolerant the incorrect pronunciation to the utmost extent, but in many occasions, they cannot stand the wrong intonation, especially when the learners have not realized the importance of intonation in English (O’ Connor \& Arnold, 1973, p. 2). Here the intonation is one of the unique prosodic features of English. China covers a vast geographic area and there are 18 districts of dialect only in terms of Chinese, which is doomed to be unavoidable for the EFL learners to be affected by the dialects.

\footnotetext{
* Acknowledgements: This research was supported by major program of National Social Science Foundation of China (15ZDB103) and by Project of Shandong Social Science (No. 17CYYJ12).

WANG Pei-juan, postgraduate, College of Foreign Languages, Shandong Agricultural University, Tai’an, China.

ZHAI Hong-hua, corresponding author, Ph.D., Professor, College of Foreign Languages, Shandong Agricultural University, Tai’an, China.
} 
And we cannot deny that the impacts of various dialects must be different on the learning of English prosody as the diverse areas of dialects varies, so it becomes much more important to know how various dialects affect learners' English prosody in details well so that actions could be taken to decline the negative effects of dialects. In this sense, the investigation on the impacts of Shandong dialects on prosody is essential to the better study and teaching of Shandong EFL learners. As for the English learning, the American linguist Gilbert (1993) once mentioned that

The students thought that they could improve their phonetic level as long as they carefully practice the pronunciation of each phoneme, but actually to master the rhythm (stress and intonation) is more important than to merely practice the pronunciation of a single phoneme, (Gilbert, 1993, p. ix)

in the preface of the Clear Speech, his well-known work. Therefore, under no circumstances can it be advisable to just learn how to read the single syllables or separate words and ignore the cultivation of prosody, especially the development of stress and intonation.

Originated in 1970s, the study on prosody has been in progress. Prosody is considered as the phonological features like intensity, duration, pitch, and so on, shown by more than one phonetic unit in the utterance. Levelt (1989) once referred to the prosody as one of the prominent aspects of oral English's outputs in his work Speaking: From Intention to Articulation. Since then, we might as well regard prosody as an independent unit that is necessary in language. Lots of attention has been paid to stress and intonation, as the major components of prosody, which gradually become researched elaborately. However, those researches laid much emphasis on the targets (stress and intonation) themselves. Hu said, "Stress refers to the degree of force used in producing a syllable. Sentence stress is much more interesting. In general situations, notional words are normally stressed while structural words are unstressed” (Hu, 2011, p. 49). Intonation involves the occurrence of recurring fall-rise patterns, each of which is used with a set of relatively consistent meanings, either on single words or on groups of words of varying length (Cruttenden, 1997, p. 7). And such kind of studies aiming at the prosody itself have emerged endlessly, but there are much less investigations on the relationship between dialects and English prosody. Even if a small number of such researches have existed, there are still few studies on the impacts of Shandong dialects on the English learners' prosody. In view of these, the present study investigates the impacts of Shandong dialects including Donglai, Dongwei, Xilu, Xiqi dialectal regions on English learners' prosody mainly from two aspects-intonation and stress. Sixteen EFL learners with each four from Donglai, Dongwei, Xilu, Xiqi dialectal regions respectively and two English native speakers are taken as subjects to record the three kinds of English sentences_-declarative sentences, questions, and exclamatory sentences, each of which has three sentences that are chosen to be considered as representative and typical.

In fact, intonation in English is much more complicated and difficult than the pronunciation, but the study of the former is pretty later than the investigation of the latter. Beginning from the late 19th century and early 20th century, the elaborate study of intonation was proposed by Henry Sweet, who connected intonation with the emotion of the speakers and the structure of sentences and designed a set of tone marks (Wang, 2008). In 1958, R. Kingdon devised a simple and practical system of tone marks which combined stress with intonation on the basis of the speakers' attitudes and emotion and the sentence structure (Wang, 2008). Since the 1990s century, a great number of researchers, such as Wennerstrom (1994), Wen Qiufang (1999), Riggenbach (2000), and so on, have 
realized that intonation is an important content in English learning and a significant component of learners' communicative competence. So far, the intonation has been in the spotlight. The researchers have found every language has its unique intonation for intonation is able to express the subtle feelings that cannot be delivered by vocabulary. For example, the appropriate intonation could promote the mutual understandings, establish a friendly relationship, and strengthen the cooperation whereas the improper intonation would arouse the misunderstanding and even hurt each other. Just as what Prof. Geofrey Leech and Prof. Jan Svartvik (1985, p. 4) wrote in the preface of the book A Communicative Grammar of English, “... effective communication in speech depends to a great extent on intonation".

Intonation and stress in the phonetics both belong to the prosodic features. Yang and Chen (2005) had already mentioned that intonation is the main part of prosody, but prosody is far wider than intonation, the former of which also involves stress, pause, and rhythm, etc. Stress plays a more crucial role in the English prosodic learning, because English is a stress-timed language and its rhythm is based on the contrast of the stressed and unstressed syllables.

The scholars, like Qian (2001) divided Shandong dialects into four dialectal regions, that is, Donglai and Dongwei dialectal regions in the eastern and Xilu and Xiqi dialectal regions in the western, each of which is different from the other. Some researchers, such as Ping (2001), once studied the influence of Henan dialects on intonation. Yang studied the Anhui dialects' negative transfer (2009) and others used to study the effects of dialects of Liaoning (Zhang, 2007), Ningbo (Mo, 2012), and other places. A small number of scholars had studied the impacts of the dialects in a city or a small area in Shandong Province. However, few of them has once investigated the common ground of the four dialectal regions of Shandong dialects on both the aspects of intonation and stress, which is what this paper will present. The previous studies either paid much attention to the pronunciation or laid much emphasis on the prosody itself. Even if it investigates the relationship of the dialects and English learning, none has kept a watchful eye on the impacts of Shandong dialects for English learners on intonation and stress. Thus the present study will make up for those defects.

\section{Experimental Design}

\section{Research Preparations}

All the sound materials are coming from AESOP (Asian English Speech cOrpus Project) which is initiated by Professor Sagisaka of Waseda University in Japan. The aim is to establish speech corpora of English learners in Asian countries. China has carried out the construction and research of the corpus in 2009. The recorded equipment used is the laptop with the built-in type audio card and microphone. The sampling rate is 22,025 HZ, the sampling accuracy is 16 bits and the sound track is mono to obtain a more dependable result.

\section{Materials}

To study the impacts of Shandong dialects for English learners on prosody, the materials have to be comprehensive, so three kinds of sentences have been set up in the study including declarative sentences, questions (special question and general questions), and exclamatory sentences with three sentences for each type. Thus there are nine sentences in total as follows: 
Table 1

List of Speech Materials in the Experiment

\begin{tabular}{|l|l|}
\hline \multirow{3}{*}{$\begin{array}{l}\text { Declarative } \\
\text { sentences }\end{array}$} & Jane may earn more money by working hard. \\
\cline { 2 - 2 } & Bright sunshine shimmers on the ocean. \\
\cline { 2 - 2 } & I said apartment five times. \\
\hline \multirow{4}{*}{ Questions } & Where were you while we were away? \\
\cline { 2 - 2 } & Can Jane come with Manny? \\
\cline { 2 - 2 } $\begin{array}{l}\text { Exclamatory } \\
\text { sentences }\end{array}$ & Did Dad do academic bidding? \\
\cline { 2 - 2 } & Wasn't it a marvelous concert! \\
\cline { 2 - 2 } & How couldn't you remember! \\
\hline
\end{tabular}

\section{Subjects and Recording}

Sixteen EFL learners of non-English majors with each four from Donglai, Dongwei, Xilu, and Xiqi dialectal regions and two English native speakers are taken as subjects to record the study materials. The sixteen EFL learners are divided into four groups, each of which has four people including two females and two males subjects. The people in the four groups come from four regions that are far away from each other and have typical characteristics of that dialectal region. It has to mention that all the subjects are born and raised in their dialectal regions and they can speak their mother dialects very fluently. What's more, every subject has to read the Chinese materials using their mother dialects before they are recorded formally.

\section{Annotation}

IViE (Intonational Variation in English) and ToBI (Tone and Breaks Indices) annotation systems are used to annotate all the recording materials to study the prosodic differences between the dialects. Normally, the following six tiers are labeled for each WAV file:

(i) Orthographic tier: the scripts of the recording words;

(ii) Phone tier: the transcripts of phonemes;

(iii) Break Index Tier (BI): showing the level of closeness between words; the transcripts of intermediate and intonational phrase boundaries, “ 3 ” marks the boundary of intermediate phrase and “ 4 ” represents the boundary of intonation phrase;

(iv) Prominence tier (PT): marking the prominent syllables;

(v) Phonetic tier (Phonetic T): the phonetic variations within an intermediate phrase;

(vi) Phonological tier (Phonological T): the phonological representations within the phrase. 


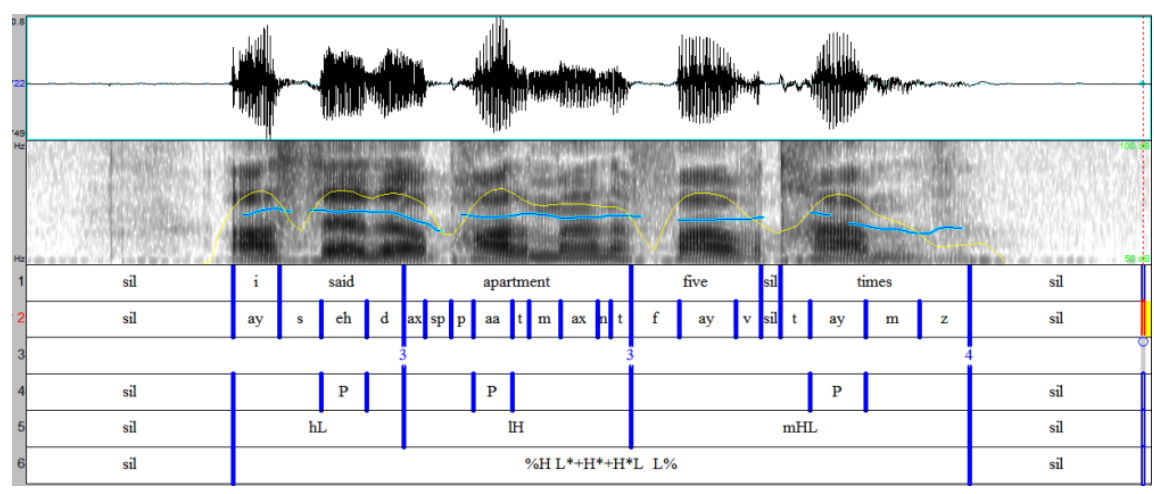

Figure 1. An annotated sample "I said apartment five times".

\section{Data Extraction and Processing}

All the recordings are saved to the list, after which they are written to the WAV files. Then Praat software is used to get their waveforms and spectrograms where the pitch, intensity, duration, formants, and pulse waves are shown. TextGrid files could be achieved by the WAV files and written to text files after a set of annotation. The next step is to make Pitchtier through deleting the outstanding and abnormal points and points representing consonants, leaving the points of vowels alone. At last, the comparison between those files of TextGrid and Pitchtier is necessary to further analyze the differences between the lingual data of the EFL learners and native English speakers.

\section{Results and Analysis}

Via listening and distinguishing repeatedly and the careful observation of the spectrograms and the drawing of Fundamental Frequency, preliminary results and analysis are reached on the basis of the contrastive analysis between intonation and stress of Shandong EFL learners and English native speakers.

\section{Intonation}

(i) Intonation is able to express the grammar structure of one sentence explicitly. For instance, declarative sentences and special questions are usually read by the falling tone and general questions are uttered by the rising tone in the normal condition. In the study, most EFL learners have a good mastery level of declarative sentences and questions. They use the tone pattern at the end of the sentences properly. However, in the exclamatory sentences, the EFL learners have different tone patterns with the ones of English native speakers. The pitch variations could demonstrate the alteration of intonation effectively. Here we take the sentence "Can Jane come with Manny?” as an example. Figure 2 is the normalized pitch after extracting from the spectrograms of the subjects using Z-score method. There are four normalized pitch contours for the learners in the four dialectal regions and one pitch contour for the English native speaker. To see it more clearly, we take the average value of the four pitch contours of EFL learners. 


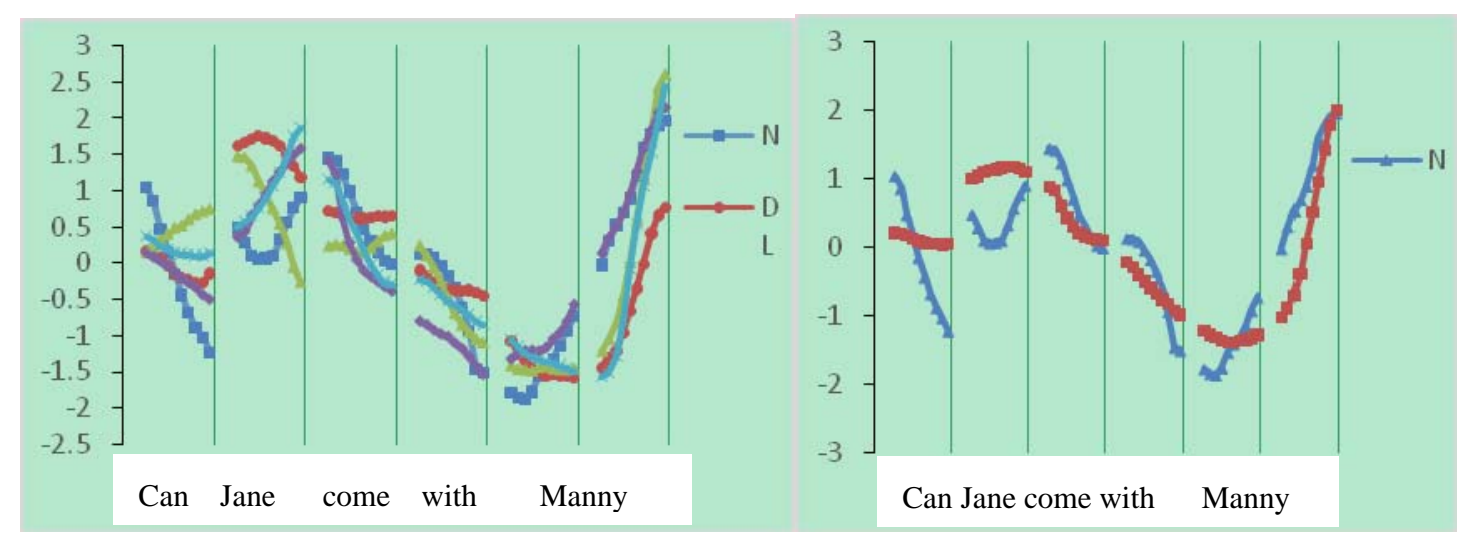

Figure 2. Normalized Pitches from different subjects. Figure 3. Pitch Comparison between Ave L and NS.

(*Note: $N$ represents the English native speaker. $D L$ means the average pitch contours of the four EFL learners from Donglai dialectal region. $D W$ stands for the average pitch contours of the four EFL learners from Dongwei dialectal region. $X L$ means the average pitch contours of the four EFL learners from Xilu dialectal region. XQ means the average pitch contours of the four EFL learners from Xiqi dialectal region. Ave $L$ represents the average pitch values of all the subjects from the four dialectal regions.)

The figures above reveal the pitch variations of the subjects' utterances for one of the questions. It can be observed that all the learners have the consciousness to have a rising tone at the end of the general question. And the overall trend of the learners' sentences are consistent with the one of the English native speaker except that the changing ranges are slightly smaller than the native speaker, especially the initial tone.

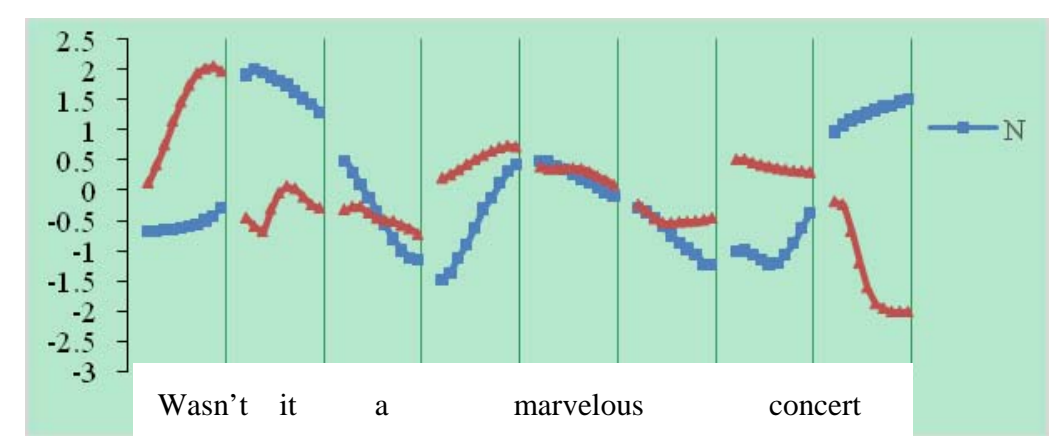

Figure 4. The normalized pitch contours of Sentence "Wasn't it a marvelous concert."

( ${ }^{*}$ represents the English native speaker. $A L$ stands for the average pitch values of the learners from the four dialectal regions.)

The trend of the two contour lines can be seen quite clearly that the former part of the sentences has similar direction. At the end of the exclamatory sentence, the native speaker used the rising tone while the learners used the falling tone. After the conversation with some learners, the conclusion is drawn that most learners just remember the fixed sentence pattern and the corresponding tone pattern rigidly without their own thinking. They did not contact the English exclamatory sentences very often in their classes and daily life, but they are used to apply the falling tone in their dialects and Mandarin. Thus they take it for granted to regard this type of sentences as the falling tone since there is no question mark. 
(ii) The Shandong EFL learners are lack of the knowledge of rhythmic group and intonation group so they just ignore the groups and make mistakes on pausing when reading the sentences.

The present study divides the intonation groups based on four standards, which are pause, anacrusis, syllable lengthening, and pitch rest (Cruttenden, 1997, pp. 29-34) during the process of labeling. It is found that the learners are not aware of dividing the rhythmic groups so that they usually utter one sentence at one blow in the investigation. That's the reason why their speaking sounds rather plain without any poetry beauty. Based on the labels, it could be concluded that the learners either never divide the intonation groups or only rely on pause consciously to divide the groups. But sometimes they also pause in the wrong position of the sentences. For example, in the sentence "Where were you while we were away?", some subjects set the same duration of pause or even longer pause after "while" than after "you”, but actually the sentence is supposed to be divided into two groups-"Where were you" and "while we were away", thus the longer pause ought to be put after the word "you” since the former part is a sense group till "you”. Their wrong partition of the groups demonstrates that they cut the sentence on the basis of the conjunction and transitional words which should not be stressed and pause after it.
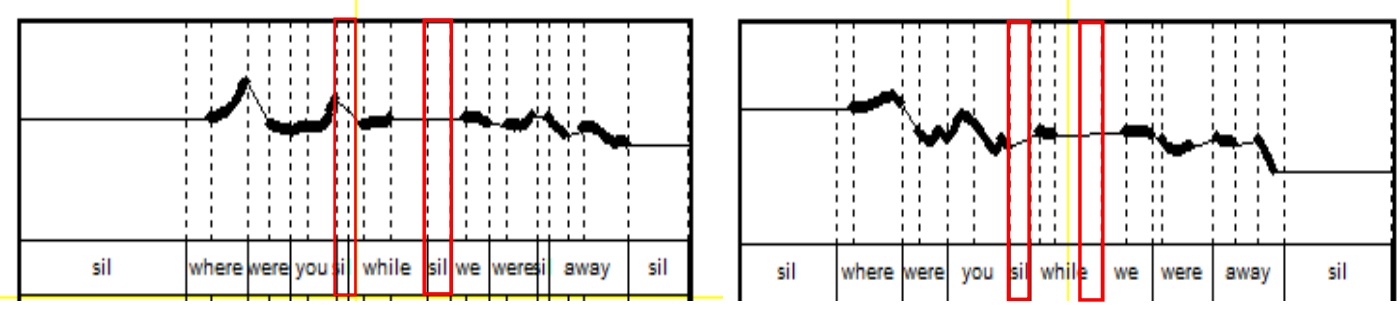

Figure 5. The partition of intonation group from subject 1. Figure 6. The partition of intonation group from subject 2.

(iii) The Shandong EFL learners tend to delay the sounds, especially the nasals / $\mathrm{n} /$, the vowels, and the final sound in the sentence. For example, when they speak the sentence "Bright sunshine shimmers on the ocean", they are likely to pronounce the diphthong /a / as long as possible and the last word "ocean" continues dragging on when pronounced.

\section{Stress}

(i) There are too many stresses in the learners' utterances so that the focuses of the sentences are not prominent. Almost every word or sound is read clearly, and even the consonants of the last word in the sentences are expressed distinctively. In this way, they are used to give each syllable the same duration and length resulting in the loss of the rhythmic sense.

It can be seen, from the Figure 7, that the learners are more likely to have several stresses in a sentence. Both the learners and the native speaker stressed the second syllable /a:/ of the word "apartment”. Besides this, the native speaker also stressed the verb "said" in the sentence while the learners put more stresses on the last two words of the sentence. This is also proved by listening. 


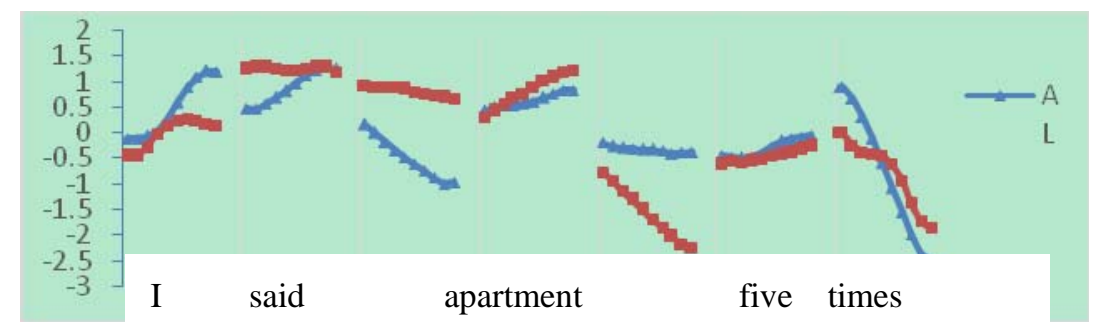

Figure 7. The normalized pitches of Sentence "I said apartment five times."

(*for $N \& A L$, the same meaning with Figure 4).

(ii) The learners read the sentences based on and full of their personal affection. As we all know, when we read English sentences, the notional words, such as noun, adjective, adverb, notional verb, numeral, interrogative, and injection, etc., ought to be stressed normally while functional words, like article, preposition, conjunction, auxiliary, modal verb, and so on, are supposed to be unstressed. But the learners do not follow these rules. Instead, they read the sentences just based on their own affection and feelings, so almost every subject has his or her own stressed point and way when reading the sentences. For example, when they read the sentence "How couldn't you remember!", the native speakers are likely to stress "couldn't" to emphasize the completion of the action. However, the learners more stress the word "remember" for they thought the verb could perform a kind of strong emotion to blame the hearer' slip from his memory and "How" owing to its burning mood and tone.

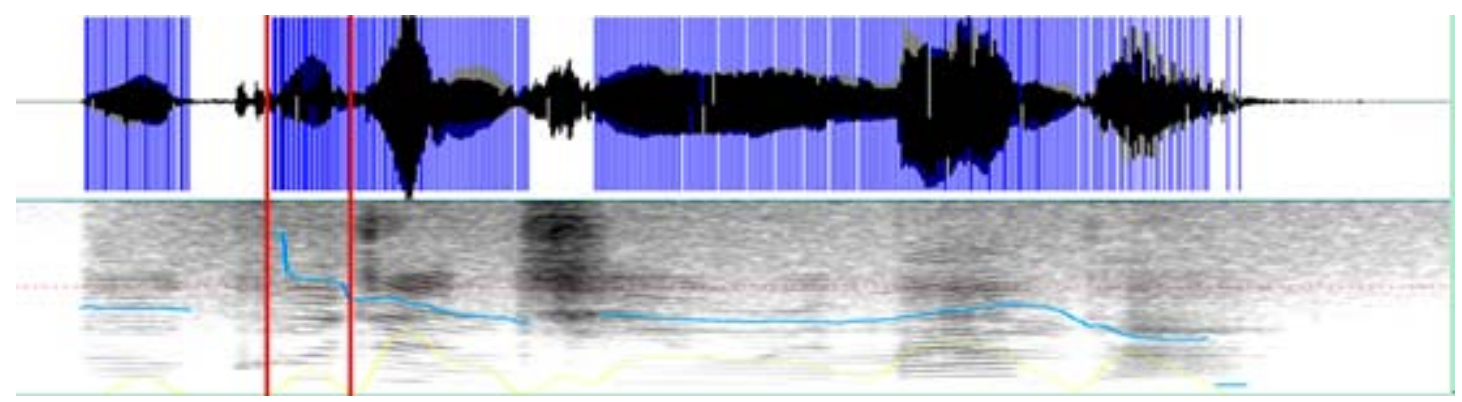

Figure 8. The pitch accent on the spectrogram of the native speaker.

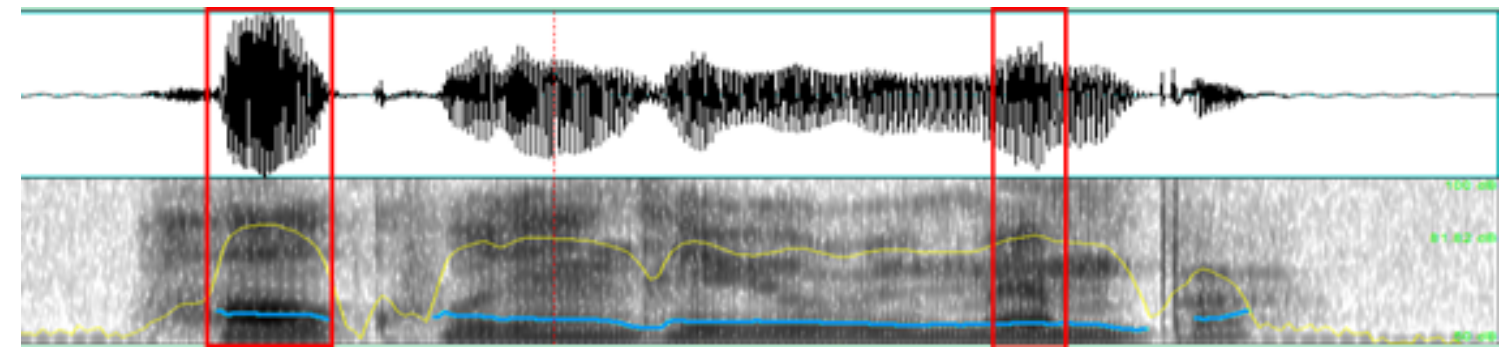

Figure 9. The pitch accent on the spectrogram of an EFL learner.

It could be observed that the EFL learners have distinct pitch and intensity contours with the native speakers. Though native speakers read "couldn't" as the stressed word, more learners stress the injection "How" and verb "remember". Such kind of differences can also occur in other sentence patterns for the reason that they are accustomed to put the stress on the words that could express their intense feelings and emotion in their opinions. 
(iii) The pauses made by the EFL learners are much more and longer than the native speakers. Shandong EFL learners tend to read the strong form rather than weak form, leading to the result that the utterances sound extremely harsh and stiff and the rhythmic beauty of English is lost. The more and longer pauses confused the listeners about the position of the real stresses.

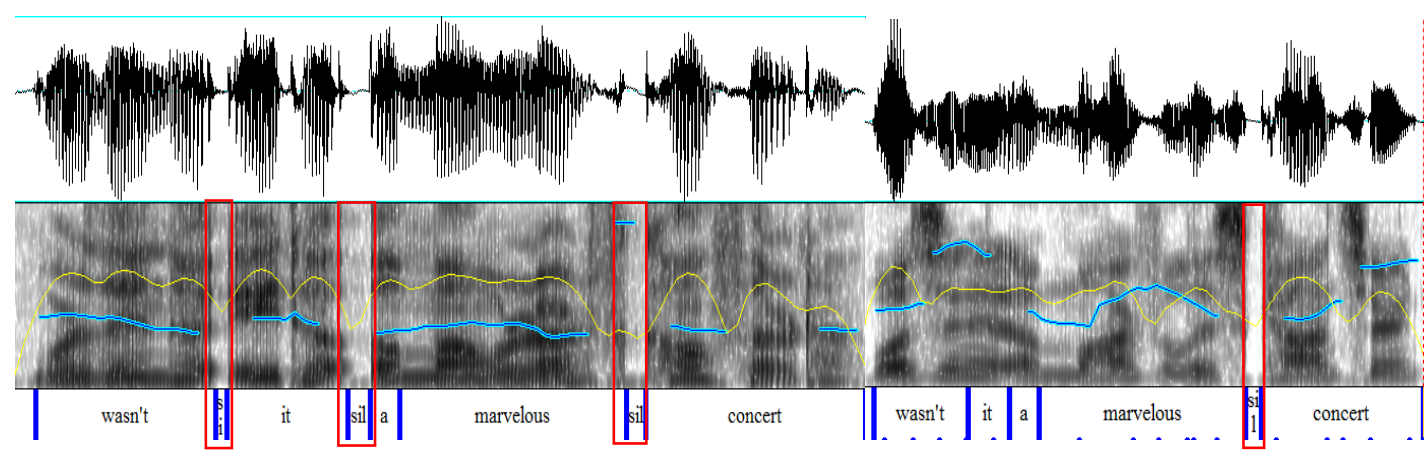

Figure 10. The performance of the EFL learner (left) and a native speaker (right).

In the short sentences, the EFL learners have 2-3 pauses on the average while the native speakers only have one pause in such kind of sentences. For example, in Figure 10, there are three pauses (marked as silence) in the spectrogram of the learner, but one pause in native speaker's.

\section{Discussion}

The reasons why the problems above occur can be concluded into three reasons generally. The first one is the interference of the native language and negative transfer of dialects. The native language plays an inseparable role in second language learning. Therefore phonetic transfer of the native language is quite common. While learning a new language, the EFL learners are always affected by the native language's habits resulting in learners' use of prior linguistic information (chiefly their mother tongue) or some physical carryover of native language surface to a second language context. Their native language's habits prevented them from learning second language's habits (Shi, 2002). More importantly, Chinese and English, in fact, belong to two completely different language families so that there are distinct differences in prosody between this two kind of languages. Thus, it is unavoidable for Shandong EFL learners to suffer the negative transfer in phonetics, especially due to their disparate dialects. As a result, the most serious problem to master English prosody is to overcome the interference of the native language, particularly their dialects for those heavy accented EFL learners. On the other hand, different types of dialects cause different impacts on the learning of prosody including intonation and stress, so teaching students in accordance of their aptitude is very important.

The second one is EFL learners taking no count of the suprasegmental features of sentences. Normally, the learners pay more attention to the pronunciation of the single words rather than the intonation and stress of sentences. Almost all the learners are asked after the study whether they know the intonation and stress of sentences. There is $48.3 \%$ in the answers that are negative. And they have little knowledge about prosody. That is another important reason why the differences take place. And the last one belongs to that the learners lack of practice and systematic learning. Most subjects are insensitive of the errors and mistakes they made for they do not know what is the right form, which means they have not received right direction when learning the English 
phonetics. Especially they seldom practice their prosody, like intonation and stress. However, Mandarin, as a tone language, differs greatly in prosody with English, an intonation language. For this reason, it is imperative to have a great amount of practice. Besides lots of practice, the basic knowledge about the prosody including intonation, stress, pause, and so on, is also necessary to be taught in order to express standard English. Practice cultivates the language intuition and in turn, theory deepens the practice. Finally, in the English prosodic teaching, the anti-interference measures should be taken on the basis of the knowledge of the problems. For instance, more training on strengthening the audition of intonation and sounding is needed.

\section{Conclusion}

The learning of English prosody, especially the study of intonation and stress, is an essential part of English learning, thus lots of efforts necessarily being made. Due to the negative influence of different learners' varied dialects, it seems to become much more difficult. Thus the present study has made an investigation on the impacts of Shandong dialects for English learners on prosody from the perspective of intonation and stress by contrast and analysis of the 16 Shandong EFL learners' lingual data and two English native speakers' phonetic materials using Praat software based on IViE and ToBi annotation systems, finding the interference of Shandong dialects on intonation and stress when the learners utter English.

Finally, it is necessary to point out that this study, as a preliminary research, unavoidably exists some limitations. At first, owing to the limitation of time and energy, the number of subjects is not too much for only 16 subjects with four learners from each region in the four dialectal regions of Shandong dialectal region, which might lead to the reduction of the accuracy. Secondly, rather short and simple sentences are chosen to present the subjects' competency of intonation and distinction between stressed and unstressed syllables, but on the other hand, the choice of these shorter and simpler sentences limits the horizon of study on the division of rhythmic groups and the conversion of tone patterns because the tone groups and the transition of tone patterns are less and unconspicuous if the sentences are shorter. Therefore, the further studies of larger ranges and long paragraphs, especially new angles of view are needed to be done.

\section{References}

Chen, H. (2006). On Chinese EFL learners' English intonation patterns. Shanghai: Shanghai Foreign Language Education Press. Cruttenden, A. (1997). Intonation. America: Cambridge University Press.

Dai, W. D., \& He, Z. X. (2013). A new concise course in linguistics for students of English. Shanghai: Shanghai Foreign Language Education Press.

Gilbert, J. B. (1993). Clear speech. America: Cambridge University Press.

Hu, Z. L. (2011). Linguistics: A course book. Beijing: Peking University Press.

Jia, Y., \& Li, A. J. (2005). An introduction to IViE English labeling system. Technical Acoustics, (3), 213-217.

Jia, Y., \& Li, A. J. (2012). Phonetic realization of accent from Chinese English learners in various dialectal regions. Proceedings of ISCSLP.

Levelt, W. (1989). Speaking: From intention to articulation. Cambridge, MA: MIT Press.

Leech, G., \& Svartvik, J. (1985). A communicative grammar of English. Shanghai: Shanghai Translation Press.

Mo, Z. Y. (2012). Negative transfer of Ningbo dialects on acquisition of English stress. Journal of Ningbo University of Technology, 24(1), 102-106.

O’Connor, J. D., \& Arnold, G. F. (1973). Intonation of colloquial English (2nd ed.). Harlow: Longman Group Ltd.

Ping, W. J. (2001). The influence of Henan dialect on English pronunciation and intonation. Journal of Henan Vocational Technical College, (3), 66-67. 
Qian, Z. Y. (2001). Research on Shandong dialects. Shandong: Shandong Qilu Press Co., Ltd.

Riggenbach, H. (2000). Perspectives on fluency. Michigan: The University of Michigan Press.

Shi, Q. Q. (2002). Transfer of Chinese sounds in the learning of English phonetics. Shandong Foreign Language Teaching, (4), 85-87.

Wennerstrom, A. (1994). Intonational meaning in English discourse: A study of non-native speakers. Applied Linguistics, 15(4), 399-420.

Wen, Q. F. (1999). Testing \& teaching spoken English. Shanghai: Shanghai Foreign Language Education Press.

Wang, W. Z. (2008). English phonology. Shanghai: Shanghai Foreign Language Education Press.

Yang, J., \& Chen, H. (2005). Prosody of spoken second language production. Foreign Languages Research, (5), 46-50.

Yang, Q. (2009). Study on negative transfer in English phonetics acquisition of students from Anhui Province. Journal of Hefei University (Social Sciences), 26(1), 124-126.

Zhang, Q. Y. (2007). The influence of Liaoning dialect on college students' English learning. Crazy English Teachers, (12), 57-60. 